\title{
UOE PIPE NUMERICAL MODEL: MANUFACTURING PROCESS AND VON MISES RESIDUAL STRESSES RESULTED AFTER EACH TECHNOLOGICAL STEP
}

\author{
DELISTOIAN Dmitri \\ Teaching assistant / Ph.D. student, Faculty of Naval Electromechanics / Department of General \\ Engineering Sciences, „Constanta Maritime University”, Constanta, Romania, dima_doni@yahoo.com \\ CHIRCHOR Mihael \\ Professor / Ph.D. , Faculty of Mechanical, Industrial and Maritime Engineering / Department of \\ Industrial Management and Road Vehicles, „Ovidius University of Constanta”, Constanta, Romania, \\ mkirkor@yahoo.com
}

\begin{abstract}
Fluid transportation from production areas to final customer is effectuated by pipelines. For oil and gas industry, pipeline safety and reliability represents a priority. From this reason, pipe quality guarantee directly influence pipeline designed life, but first of all protects environment. A significant number of longitudinally welded pipes, for onshore/offshore pipelines, are manufactured by UOE method. This method is based on cold forming. In present study, using finite element method is modeled UOE pipe manufacturing process and is obtained von Mises stresses for each step. Numerical simulation is performed for L415 MB (X60) steel plate with 7,9 mm thickness, length $30 \mathrm{~mm}$ and width $1250 \mathrm{~mm}$, as result it is obtained a DN 400 pipe.
\end{abstract}

Key words: von Mises stresses, UOE, strip, punch, die

\section{Introduction}

Finite element method is a numerical method for solving problems of engineering and mathematical physics. Useful for problems with complicated geometries, loadings, and material properties, where analytical solutions cannot be obtained and is used to obtain solutions for various appilcations, which includes [1]:

- Stress analysis;

- Heat transfer;

- Electromagnetic fields;

- Fluid flow, etc; version [3].

For residual stress numerical simulation is using engineering software ANSYS R16.2 student

Before numerical simulation starting, is need to explain UOE pipe manufacturing process. Based on international abbreviation UOE (Figure 1), manufacturing process is presented by 3 principal technological steps, so: $\mathrm{U}$ - represents when plate is formed into $\mathrm{U}$ - shape (Figure $1 \mathrm{~b}$ ), $\mathrm{O}$ represents the moment when $U$ shape is pressed into circular shape (Figure 1c) and final step E (Figure 1d) - represent pipe expanding operation to obtain standard size of pipe by applying radial oriented internal pressure, but always, first step is edge crimping operation (Figure 1a) that means edge preparing for weld seam execution, i.e. plate edges crimping into circular shape.

Numerical simulation of pipe manufacturing process is divided in next order:

- Edge crimping;

- Material relaxing after loading;

- "U" shape;

- Material relaxing after loading;

- "O" shape;

- Material relaxing after loading; 


\section{ACTA UIVERSITATIS CIBINIENSIS - TECHNICAL SERIES}

Vol. LXIX 2017

- Expanding;

- Material relaxing after loading;

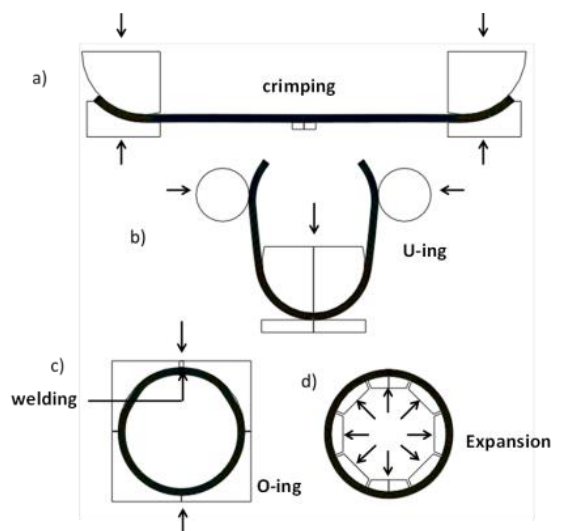

Figure 1: UOE forming steps (2) of the pipe.

Considering symmetry and geometry of the pipe, numerical simulation is performed for half

According to [4] to characterize a state of stress for more principal directions it is established an equivalent tensile stress, which is compared with admissible stress. This equivalent tensile stress is also called equivalent stress or von Misses stress. Equivalent stresses or von Mises stress, which appears during the process, are calculated using total strain energy per unit volume theory and it is represented in the following form [4]:

$$
\sigma_{\text {Mis }}=\frac{1}{\sqrt{2}} \sqrt{\left(\sigma_{x}-\sigma_{y}\right)^{2}+\left(\sigma_{y}-\sigma_{z}\right)^{2}+\left(\sigma_{z}-\sigma_{x}\right)^{2}}
$$

Numerical simulation is performed for the next initial data [5]:

Plate width - $1250 \mathrm{~mm}$;

Plate thickness $-7.9 \mathrm{~mm}$;

Yield point $-\sigma_{c}=478 \mathrm{MPa}$;

Ultimate stress - $\sigma_{r}=597 \mathrm{MPa}$;

For indexing, for each step, von Mises stresses are indexed using international abbreviation for manufacturing process - UOE, namely [6]:

$$
\begin{aligned}
& \text { Edge crimping }-\sigma_{J}^{M i s} \\
& \mathrm{U}-\sigma_{U}^{M i s} ; \\
& \mathrm{O}-\sigma_{O}^{M i s} ; \\
& \mathrm{E}-\sigma_{E}^{M i s} ;
\end{aligned}
$$

Simulation results of the manufacturing process are presented in sections below.

\section{Edge crimping modeling}

Plate preparing, for welding joint execution, it is very important step for future pipe quality: For good result after welding joint execution, edges must be parallel to each other.

Edge crimping process is based on cold forming principle. For cold forming operation, need a punch die couple. Punch die couple is composed of punch 1, die 2 and strip 3. Punch bending radius is calculated depending on steel proprieties and spring back [7]. Die bending radius is calculated considering plate thickness.

Principle is the next: as shown in figure 1, punch 1 is driven by hydraulic press crosshead and has vertical movement till the moment when plate is obtained circular shape. 
Vol. LXIX

Figure 2: Punch die couple schematic representation

Forwards in figure 2 are represented maximum von Mises stresses distribution, which appears during edge crimping operation.

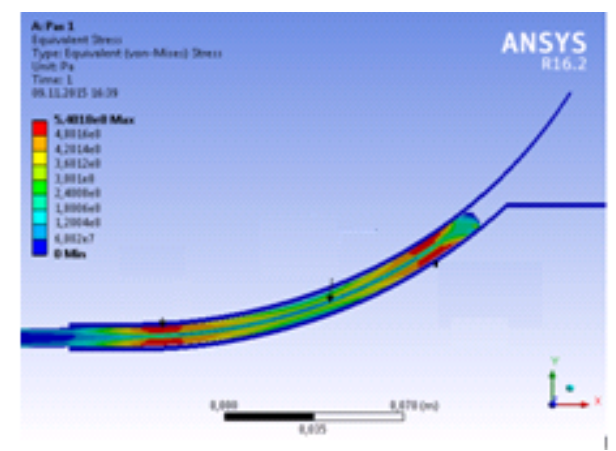

Figure 3: Von Mises stress $\sigma_{\text {Jmax }}^{\text {Mis }}$ distribution in cold formed edges

The value of these stresses is around $\sigma_{J \max }^{M i s}=540 \mathrm{MPa}$. Position of the highest values of the von Mises stresses is in passing from plane to circular shape. In the figure 4, is presented von Mises stresses evolution during punch action. As shown, crimping process is starting with null values of von Mises stresses $\sigma_{\text {Jmax }}^{\text {Mis }}$ and gradually increases to maximum values. Must be mentioned, that maximum values represents the moment when strip took punch shape.

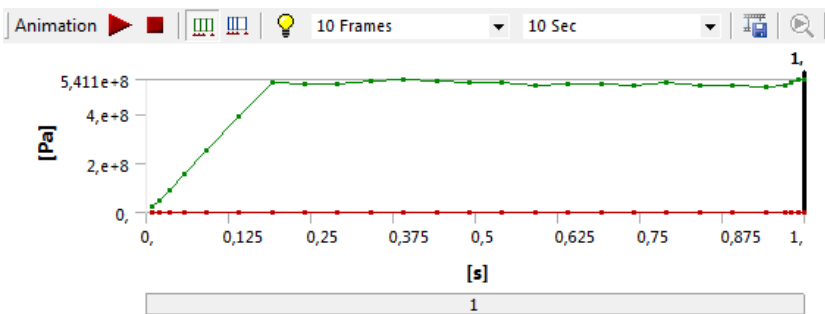

Figure 4: Von Mises stresses $\sigma_{I \max }^{\mathrm{Mis}}$ during punch action

\section{2. „U” shape modeling}

Next step is $U$ shape obtaining. The principle is the same, but implies strains on bigger area and length. Punch die couple is composed of punch 4 with bending radius $R=171,135 \mathrm{~mm}$ [8], (calculated depending on steel proprieties and spring back and compared with manufacturer's data), and piece 5, which has a die role (Figure 5). 


\section{ACTA UIVERSITATIS CIBINIENSIS - TECHNICAL SERIES}

Vol. LXIX 2017

In this case, piece 5 is going up pushing strip 3 to bend around punch 4 .

In that section is simulated $U$ shape obtaining and is presented von Mises residual stresses evolution starting with edge crimping operation and finishing with residual stresses that remains after U shape operation.

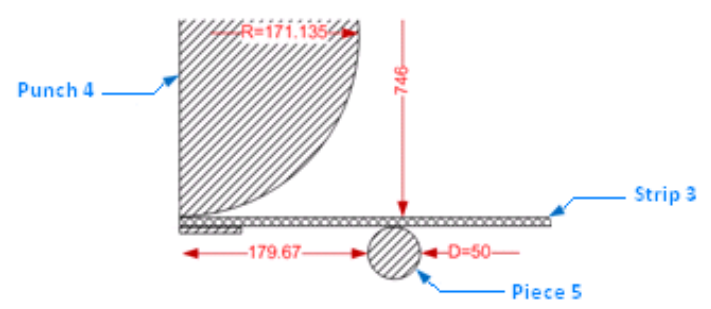

Figure 5: Punch die couple schematic representation for $U$ shape

In figure 6 is presented obtained $U$ shape, and in the figure 6 is presented von Mises stresses evolution. As shown in figure 7, $\mathrm{U}$ shape process begins with residual stresses remained from edge crimping, continues to maximum stress values and finishing with residual von Mises stresses remained after $\mathrm{U}$ shape operation.

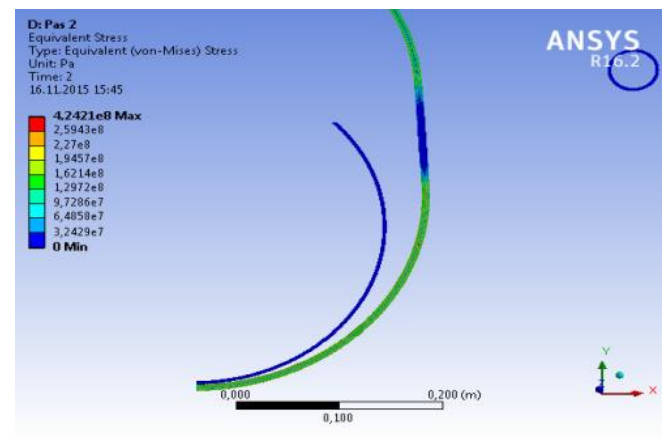

Figure 6: Von Mises residual stresses $\sigma_{\text {Ures }}^{\text {Mis }}$

According to figure 7, residual von Mises stresses remained after edge crimping have values of $-\sigma_{\text {Jres }}^{\text {Mis }}=238 \mathrm{MPa}$ and residual von Mises stresses remained after $\mathrm{U}$ shape have values of $\sigma_{\text {Ures }}^{\text {Mis }}=424 M P a$. As shown in figure 6 , in red color small points are biggest values of stresses, but this point represents mesh discretization errors. From this reason, these points are ignored and residual von Mises stresses average values are situated around $\sigma_{\text {Ures }}^{\text {Mis }}=162 \mathrm{MPa}$.

Difference between residual stresses is $\sigma=76 \mathrm{MPa}$. This value demonstrates that in $\mathrm{U}$ press operation, cold forming occurred a bigger area and length and this leads directly to section modulus $\mathrm{W}$, which influence stress value.

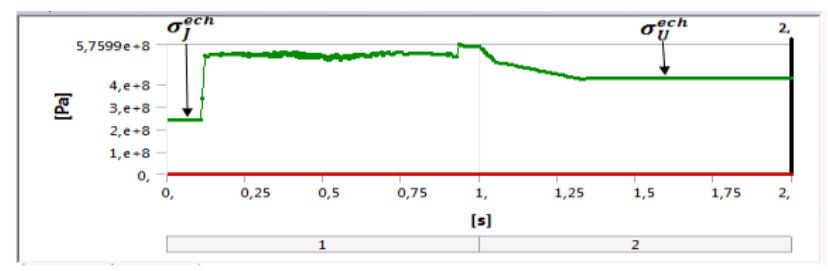

Figure 7: Von Mises stress $\sigma_{.}^{\text {Mis }}$ evolution 


\section{ACTA UIVERSITATIS CIBINIENSIS - TECHNICAL SERIES}

Vol. LXIX 2017

\section{3. "O" shape modeling}

This operation represents the moment when the $\mathrm{U}$ - shape is pressed into the circular shape. From this moment the strip is a pipe, but with high values of ovality $\Delta_{o}$. In the reality for $\mathrm{O}$ shape modeling is using hydraulic $\mathrm{O}$ - press, but for numerical modeling the $\mathrm{O}$ press role is taken by piece 6 (punch) and piece 7 (die). Piece 7 is fixed element and piece 6 is mobile element with vertical movement. For this step, bending radius is $R=203 \mathrm{~mm}$, because is closed frame press operation and value radius represents outside pipe radius. Principle is the next: $U$ shape is positioned between movable and fixed elements. Process is starting with vertical movement of mobile part and continues till the moment, when $\mathrm{O}$ - shape is obtained.

In figure 8 , is presented $\mathrm{O}$ pres schematic representation.

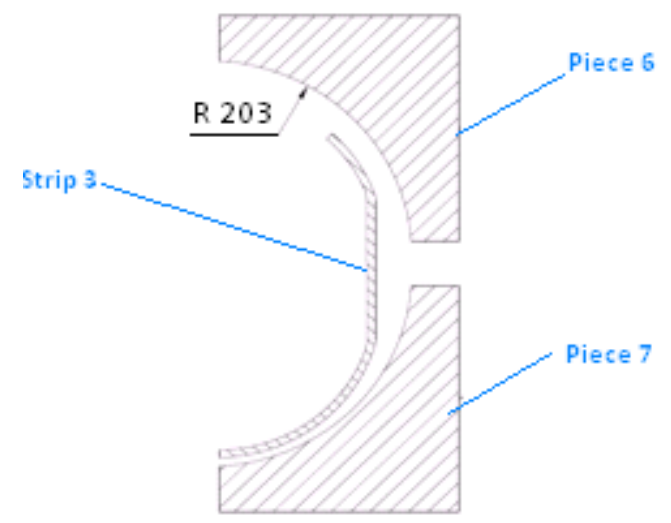

Figure 8: „O” press schematic representation

As shown in figure 10, modeling is beginning with von Mises residual stresses remained after $\mathrm{U}$ shape modeling and continue to the maximum values.

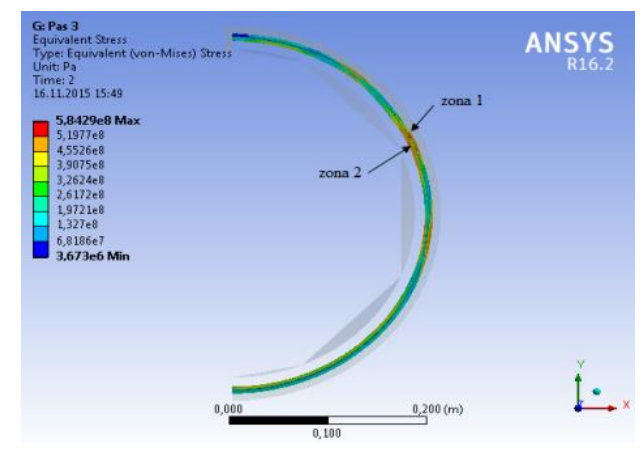

Figure 9: Von Mises maximum stresses $\sigma_{0 \text { Max }}^{\mathrm{Mis}}$

As presented in figure 9, Von Mises maximum stress values are situated in stress concentration and values is $\sigma_{\text {Omax }}^{\text {Mis }}=584 \mathrm{MPa}$, but average values are around $\sigma_{\text {Ores }}^{\text {Mis }}=326 \mathrm{MPa}$.

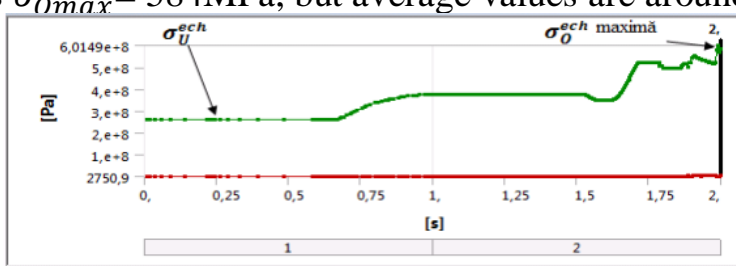




\section{ACTA UIVERSITATIS CIBINIENSIS - TECHNICAL SERIES}

Vol. LXIX 2017

Figure 10: Von Misses stress $\sigma_{.}^{\text {Mis }}$ evolution

\section{Pipe expanding modeling}

Last and most important is pipe expanding operation. In the reality, principal is following: mechanical expander produces radial oriented internal pressure for plastic strain creation [9], but for numerical simulation, expander will be replaced just by radial oriented internal pressure.

Being based on API SPECIFICATION 5L [10] pipe is to be expanded to a ratio of - greater than $0,3 \%$ and less than or equal to $1,5 \%$. In this case, pipe will be expanded to a ratio of $0,8 \%$. In figure 10 is presented pipe with high values of ovality $\Delta_{o}$, and with extensive deformation areas. To note that these areas are corresponding with areas resulted after cold forming operations from the previous steps.

As shown in figure 11, pipe loading with internal pressure beginning with high level of ovality $\Delta_{o}$ and maximum value of residual stresses is $\sigma_{\text {Ores }}^{\text {Mis }}=405 \mathrm{MPa}$.

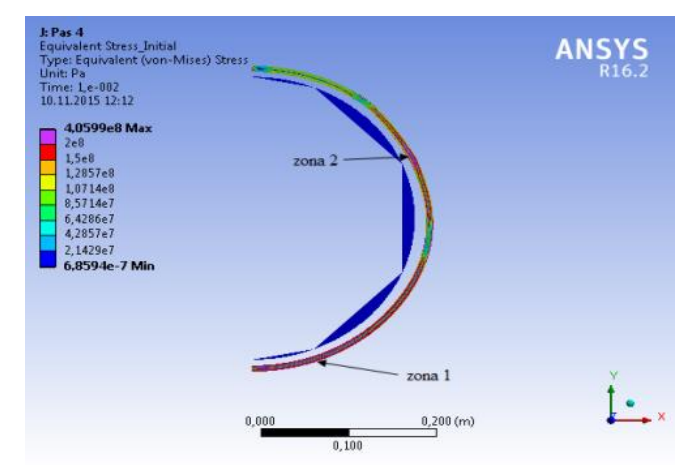

Figure 11: Von Mises maximum stresses after "O" shape modeling

After pipe loading, as shown in figure 12, average values of residual stresses are situated around $\sigma_{E r e s}^{\text {Mis }}=64 \mathrm{MPa}-128 \mathrm{MPa}$, but highest values are situated in the same stress concentration area, as presented in figure 8 .

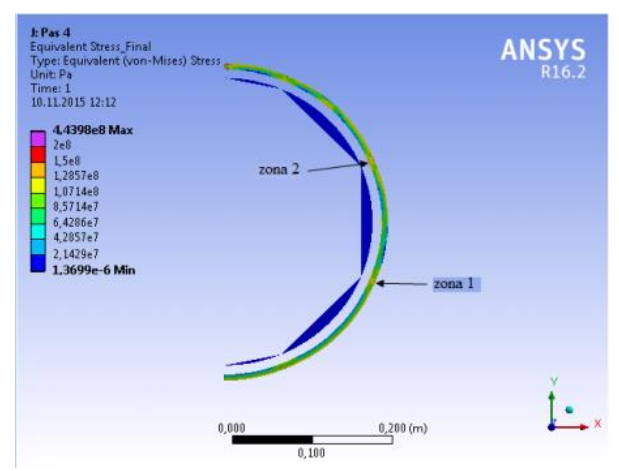

Figure 12: Von Mises residual stresses after expanding

In this area von Mises maximum stresses values is around $\sigma_{\text {Eres }}^{\text {Mis }}=444 \mathrm{MPa}$. Hereafter in figure 13 is presented von Mises stress evolution. 
Vol. LXIX 2017

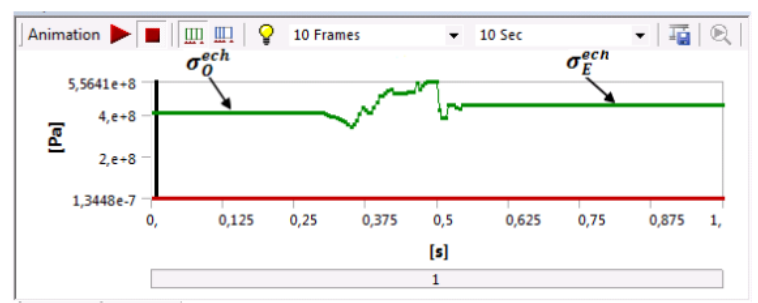

Figure 13: Von Mises stress evolution

After expanding simulation, pipe body shows a uniform stress distribution, but areas with high level of stresses do not disappear and remains in pipe body for all lifetime.

\section{Conclusion}

Manufacturing process simulation using finite element method revealed the next aspects.

Process is starting with edge crimping operation, as a result has obtained von Mises residual stresses values of $\sigma_{\text {Jres }}^{\mathrm{Mis}}=238 \mathrm{MPa}$. These values are located in areas with crossing from plane to circular shape.

Next step is a moment when strip is pressed into the $\mathrm{U}$ - shape. After this operation von Mises residual stresses values are situated around $\sigma_{\text {Ures }}^{\text {Mis }}=162 \mathrm{MPa}$. Between residual stresses resulted from the previous operation an $\mathrm{U}$ - press, exists a difference of $\sigma=76 \mathrm{MPa}$., but for the same value of bending radius. This fact leads to section modulus $\mathrm{W}$, because stress value is depends on geometrical characteristics of the section, for big values of the section, for the same bending moment, stress values decreases

Last step regarding bending is $\mathrm{O}$ - shape operation. In this moment the $\mathrm{U}$ - shape is pressed into the circular shape. From this moment plate is becomes pipe. Von Mises residual stresses average values are situated around $\sigma_{\text {Ores }}^{\text {Mis }}=326 \mathrm{MPa}$. After $\mathrm{O}$ press operation appeared stress concentration with values of $\sigma_{\text {Ores }}^{\text {Mis }}=584 \mathrm{MPa}$.

Last and most important step represents pipe expanding operation. This step represents the moment when pipe is entirely cold formed in plastic zone, by applying internal radial oriented pressure. Von Mises residual stresses average values are situated around $\sigma_{\text {Eres }}^{\text {Mis }}=128 \mathrm{MPa}$, but the same stress concentrator that remained after $\mathrm{O}$ press operation, register a high value of stresses, which are situated around $\sigma_{\text {Eres }}^{\text {Mis }}=444 \mathrm{MPa}$.

Below are presented figures with Von Mises residual stress evolution during modeling. In figure 14 is presented the best case of stress evolution, with stress reduction after expanding, but in figure 14 are presented values resulted from stress concentration areas.

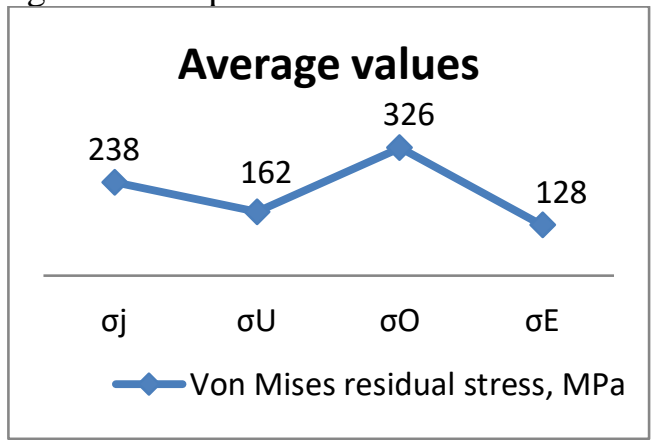

Figure 14: Von Mises residual stresses average values

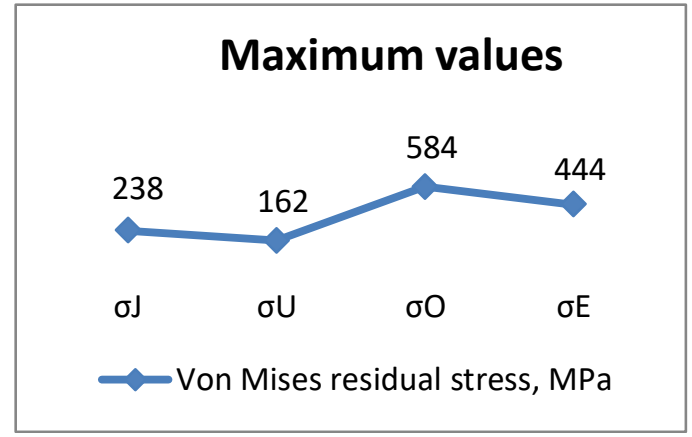

Figure 15: Von Mises residual stresses maximum values 


\section{ACTA UIVERSITATIS CIBINIENSIS - TECHNICAL SERIES}

Vol. LXIX 2017

Even if, after pipe expanding operation average values are situated around $\sigma_{\text {Eres }}^{\text {Mis }}=128 \mathrm{MPa}$, on pipe surface remains stress concentrator with value of $\sigma_{E r e s}^{M i s}=444 \mathrm{MPa}$, which represents $93 \%$ of yield point $\sigma_{Y}=478 \mathrm{MPa}$. Stress value position near the yield point plus sum of stresses resulted from pipe launching, pipeline operation and stress corrosion cracking phenomenon, may negatively affect pipeline lifetime .

\section{References}

1. Petr Krysl, A pragmatic introduction to the Fihite Element Method for thermal and stress analysis, Pressure Cooker Press, pp 91-92, San Diego, USA (2005).

2. Giannoula Chatzopoulou, George Varelis, Effects of UOE manufacturing process on pressurized bending response of offshore pipes, 10th International Pipeline Conference, IPC2014-33321, pp. 534-536, Calgary, Canada, (2014).

3. Finite Element Analyses, www.ansys.com ANSYS R16.2, student version, (2016).

4. Ion Tudose, Rezistenţa materialelor Ed. Didactică şi Pedagogică, pp 212-214, Bucureşti, Romania (1981).

5. Dmitri Delistoian, Studiul numeric si experimental al tensiunilor reziduale din procesul de fabricatie a conductelor magistrale, Raportul de cercetare Nr. 3, Constanta Maritime University, pp 8-9, Constanta, Romania (2017).

6. EuroPipe - Mulheim Pipecoatings, UOE pipe manufacturing process, http://www.europipe.com/products/manufacturing-process/, Mülheim an der Ruhr, Germany, (2017). (Accessed 10/06/2016)

7. Leonid Rudmann, Spravochnik constructora shtampov, Izd. Mashinostroenie, pp 202-204, Moskow, URSS (1988).

8. Dmitri Delistoian, Studiul numeric si experimental al tensiunilor reziduale din procesul de fabricatie a conductelor magistrale, Raportul de cercetare Nr. 3, Constanta Maritime University, pp 12-15, Constanta, Romania (2017).

9. Hunan Great Steel Pipe CO.LTD, Difference between UOE and JCOE pipe, http://www.hnssd.com/news.asp?id=460, Hunan, China (2017). (Accessed 20.09.2016)

10. API SPECIFICATION 5L Specification for line pipe, pp 20-21, Washington, USA (2008). 